\title{
A way of undertaking a research phase in graphic design
}

\author{
Younjoon Lee $^{1^{*}}$ \\ ${ }^{1}$ Visual Communication Design, Hongik University \\ 그래픽디자인 리서치 수행에 관한 연구 \\ 이연준 ${ }^{*}$ \\ ${ }^{1}$ 홍익대학교 시각디자인학과
}

\begin{abstract}
This paper highlights the importance of design research and encourages an understanding of design tools that engage society and people. Twenty groups, a total of sixty students, were asked to participate in this project and they used an IDEO tool kit. A total of three surveys were given. One survey was given to the participants before participating in the project and another after the project. The last survey was given to six experts to evaluate the students' work. Preliminary analysis found that students, prior to participating in the project, replied heavily on Internet research and a literature review, and did not display a structured research process. Primary analysis showed that the groups that spent more time on research and utilised design tools performed better, particularly those utilising 'observation' techniques.

요 약 본 논문은 그래픽 디자인에서 디자인리서치의 중요성과 사회와 인간과 함께하는 디자인적 방법(Design tools)의 이해 고취가 목표이다. 본 연구는 총 60 명을 대상으로 연구를 진행하였으며, 참여자들은 $\mathrm{IDEO}$ 툴킷(방법)을 활용하였다. 총 세 개의 설문조사가 이루어졌으면 두 개의 설문지는 동일한 형태로 프로젝트 참여 '사전'과 '사후'에 각각 사용되었다. 마지막 은 학생들의 작업을 평가하기 위해 전문가 6 인의 조사가 이루어졌다. 예비분석에서는 학생들의 프로젝트 이전의 리서치 경향 인터넷과 문헌자료에 의존도가 매우 높고 체계적인 연구의 형태를 보이지 않았다. 본 분석을 통해서는 리서치에 많은 시간을 할애하고 디자인적 방법을 사용한 그룹의 평가가 긍정적으로 나타났다. 특히, '관찰'기법을 이용한 그룹의 긍정적 평가가 높 게 나타났다.
\end{abstract}

Key Words : Graphic design, Design research (Research through design), Design tools in research

\section{Introduction}

Until recently, an important role of design has been highlighted which is to help lucrative growth by using innovative or stylish artefacts to lure consumers in businesses. Corporations have employed design as a core economic driver in order to sustain their businesses [1]. Designers have focused on acquiring the skills that corporations and design practice require in order to complete tasks in business contexts [2].
Since design's role is currently shifting towards resolving 'wicked problems' and creating values for the economy and society, design demands a transition towards the incorporation of social needs and responsibilities [3,4]. This transition was embarked upon industrial design in order to understand users or eliciting the latent users' needs rather than identifying representatives (targets): i.e. employing user-centred methods and attitudes, e.g. scenario building, user involvement in the early stages of the design process

*Corresponding Author : Younjoon Lee(Hongik Univ.)

Tel: +82-2-320-1951 email: younjoonlee@hongik.ac.kr 
(participatory methods), etc. [5].

However, this shift is limited to a few design fields, such as industrial or interaction design, and has yet to cross into the realm of graphic design. Researchers [5-9] have criticised traditional graphic design pedagogy and advocated that graphic design education should encounter the new era of design - the third and fourth orders of design in Buchannan's aforementioned notion: process, system and environment; design needs to be adaptive in changing and complicated environments [6]. Current graphic design education must become involved in much broader contexts, going beyond business and personal expression [8].

Tyler also claims that "to educate our students as citizens, we must provide them with the skills to understand how we give voice and how we affect society in all our communication devices" [10, pp.351]. Forlizzi and Lebbon asserted that due to the complexity of problems, relying solely on the designer's intuition might no longer be the most effective approach [9]. To enable communication and take on a new role for design - value generation and social and environmental impact - graphic designers must now employ empathy in order to access and understand people. Hence, "research plays an increasingly important role in this transition [the change of design needs according to social evolution]" [11, pp.10].

Despite the importance of design research, graphic design education shows a complacent attitude as regards expanding beyond the traditional realm [7]. Therefore, this paper investigates ways of undertaking a research phase and using design methods (tools) in graphic design. Then, it aims to identify how research performance impacts on students outcomes. Through exploring a role for and considering impact of design research in graphic design, this paper provides an idea of how to utilise design research and methods in order to correspond to design's current responsibilities by going beyond crafting artefacts for commercial ends and personal expression.

\section{Theoretical framework}

Previous work on design research was inadequate and relatively few journals were dedicated to design research in graphic design [5]. Most work on design research has been conducted within design fields in which user-centred research is common, such as industrial design or human-computer interactions [5] or has been employed to a limited degree at post-graduate level [3]. Most of all, there was little research on how design could research can influence outcomes, e.g. to what extent can outcomes be affected by design research? Morrison, at Oslo School of Architecture and Design (pp.4), asserts that, overall, "Design research still has trouble achieving visibility, not least because the concept itself is tricky to define". Such uncertainty over utilising design research impedes the application of design research [12].

The term 'design research' was coined instead of research in design as a discipline and conforms to a rationalistic assumption [11]. It shifted to Donald Schön's pragmatist perspective of perceiving design as a sense-making entity rather than problem-solving in the 1990s after criticising the limits of rationalism from a phenomenological perspective. Due to the evolution of design's role, the annotation of design research is varied. Thus, it is first necessary succinctly to define what design research actually is.

Frayling, from the Royal College of Art, categorised research in art and design into three categories: 1) research into design: traditional historical and aesthetic studies of design, 2) research through design: project-based and includes materials research and development, and 3) research for design: create objects and systems that display the results of research and prove its worth [13]. While design academia mostly works on research into design in terms of building theory, design practitioners tend to conduct research for design. In Margolin's note (cited in Roth), design studies is a 'basic enquiry in design', which is similar to Frayling's concept, 'research into design'. Margolin's stance of 'design research' incorporates 'research for 
design' and 'research through design', which relate to projects (practices) [5].

Stemming from 'research through design' from Fraying, design research branched out as follows: generative design research - producing ideas and finding insights through a human-centred approach; participatory design research - involving users in the early or front stages of the process [14]; constructive design research - emphasising project (practice)-based research [11]. Cooper (Cited in Collins) notes that [15, pp.23], "Since the 1980s there has been growing interest in design from the social sciences, psychology, marketing and other management areas. This has led to a rich culture of design research." According to Press (1995, cited in Swann, 2002) [16, pp.52], “A design artifact is a researched proposition for changing reality." A final outcome in design is a proposition elicited from the knowledge acquired through research.

Along with the proliferation of design research, as the design methods movement and user-centred approaches have converged into the concept of 'research through design', ways of design(er) enquiry into new knowledge have started to be applied throughout practices, rather than adopting classical quantitative and qualitative research techniques. The concept of 'Design Thinking [17]' leverages and expands the role of design research towards 'generative' research. This enables enacting new methods as well as traditional design methods, such as collage, scenarios, etc. which are actively utilised in a new type of design consultancy (e.g. IDEO) or a service design consultancy (e.g. Engine and Livework) such as experience prototype, role play, etc. [11]. That is, to access and understand users (humans) behaviours, needs and system, diverse methods and tools that are developed and utilised in practice.

\section{Conceptual background and Hypothesis}

This paper has three objectives. First, it analyses the proportion of the research phase within the whole design process to better understand ways of utilising research in graphic design education. This sheds light on how graphic design students undertake research. Second, it analyses how a change in proportion in the research phase impacts on research performance. Third, it analyses how research performance impacts outcomes depending on the tools applied in a project: 1) design ways vs. classical ways and 2) observation tools vs. doing tools. The initial one intends to identify if there is a difference in applying design ways (employing seeing or doing tools) and classical ways (employing traditional ways in social science: survey, typical type of interview, etc.). The latter one intends to explore if there is a difference in applying seeing and doing tools.

The conceptual framework and hypothesised paths are depicted in [Fig. 1].

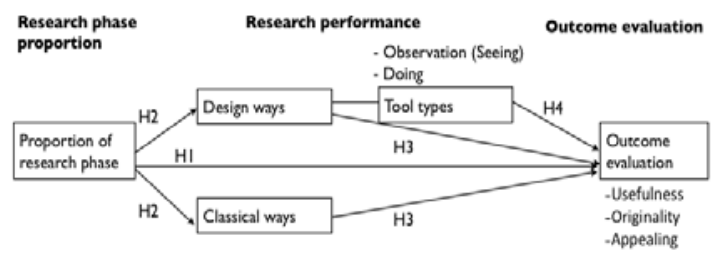

[Fig. 1] Conceptual framework

\subsection{Design research phase's impact}

The world's challenges are becoming more formidable and the role of research in design is keen to understand people, cultures and belief systems [18]. Subsequently, conducting design research is getting noticed and the results from design research are being studied. Researchers assert that design research leads practitioners to have a positive impact. Buchanan posited that despite the discourse concerning the controversial needs of design research, this research does opens up opportunities to pursue new knowledge which connects/integrates with human beings and the world and thus to act in a practical manner [3]. While Buchanan points to a role of design research as practical (useful) knowledge, Heller notes that research 
is not confined to creative competency but can expand creative freedom [19].

There is, however, little evidence on how research phases can influence outcomes, e.g. the proportion of design research and/or how ways of applying design methods determine outcome traits. While some may not agree with quantifying results, it is worth establishing the relationship between the proportion of research, the methods subsequently chosen and the results in a quantitative manner. In addition, from the literature, graphic design is criticised for deficiency of attitude toward applying design research, so this study focuses on investigating how proportion change of design research will influence the outcome(s) of a project in graphic design.

Thus, the following is posited:

H1: A change in the proportion of the research phase influences the outcome(s) of a project.

H2: A change in the proportion of the research phase influences ways of employing methods.

\subsection{Design research methods' impact}

Classical research methodologies are considered twofold: qualitative and quantitative. While quantitative methods are mostly used for value-free enquiry through an objective lens, qualitative methods are used for value-bound enquiry through a constructive lens. There is lively debate about how to conduct research in design academia, especially in terms of quantifiable research in design.

Hanington (ed. by Sanders and Stappers, 2012) posits that "Design research is an inherently creative activity, and should therefore be flexible, allowing appropriateness to be the determining factor in selecting the best methods for information collection, guiding inspiration, and testing ideas" [14, pp.34]. Even though experience counts in choosing better propositions, previously design theory focused less on user observation as a source of innovation [6]. Design research which branched out from the social sciences combines classical methods with designer's ways of seeing and doing.

Sanders and Stappers note that different types of research techniques derive different degrees of information or knowledge from users and research contexts [14]. For example, through interviews or similar methods of asking people questions, a researcher mostly obtains explicit rather than tacit or latent knowledge: interview and survey in a classical way is used in social science and business disciplines. To choose appropriate methods, a human-centred approaches needs to be widely taken up within design research. Sanders asserts that, depending on the methods or techniques, the findings which researchers can obtain are predetermined, e.g. explicit knowledge can be attained through interviews ('saying' techniques), observative knowledge can be attained through observation (such as ethnography, flying on the wall, etc.), and tacit and latent knowledge can be attained through 'doing' techniques (generative sessions, co-prototype, body-storming, etc.) [20].

Mintzberg and Westley posit that while observation techniques are appropriate to combine diverse elements for creative solutions, 'doing' techniques are better to find a solution in an ill-defined or disruptive context [21]. Especially, generative sessions are stressed to involve people and produce ideas and insights along with the rise of service design.

Despite that, user engagement has often been blamed for disruptive solutions [22, 23]. On the other hand, observation is less contentious; emphatic observation is a good way to interpreting human behaviour [18]. Sanders and Stappers note that 'saying', 'seeing' and 'doing' techniques 'complement and reinforce each other', [14, pp.66] and therefore it is ideally better to combine techniques in a flexible manner. However, it is often impossible to combine all the different techniques in a project due to the project schedule, supports, etc.

Thus, it is worth identifying if there is a difference in employing design ways (designers ways of seeing and doing) and classical ways (ways applied 
traditionally in social science and business), and which techniques produce better outcomes and putting hints into curriculum configuration. In this paper, the following hypotheses are proposed:

H3: Ways of employing research tools - more 'design' or 'classical' tools - in the research phase influence the outcome(s) of a project.

H4: Ways of employing tools - more 'observation (seeing)' or 'doing' tools - in the research phase influence the outcome(s) of a project.

\section{Data Collection}

This section describes a project given to students, the conditions and the data process.

\subsection{Project conditions}

The project aim was to develop a service to improve 20s' health and a brand system through verifying design research. The topic was selected to promote students' accessibility to users. Sixty students were involved in this project and split into twenty groups of three. Amongst the students there were three exchange students, and each of them was put into a different group. Each group was taught about design research and instructed to utilise at least three tools from the IDEO tool kit, which were configured to understand people's behaviours. IDEO proposes 'IDEO tool kit', which consists of four phases: learn, look, ask and try, and both classical, e.g. desk research, competitor analysis, survey, etc., and designer's techniques, e.g. rapid prototyping, cultural probe, shadowing, etc., in order to help people to use them across project phases.

Although the importance of design research was highlighted in the class, students were not forcefully instructed to choose specific design tools such as scenario, rapid prototyping, cultural probe, etc. Within the project, an affinity diagram and customer journey mapping to diagnose the contexts each group framed were mandatory. These tools were not included for the analysis. Project duration was seven and half weeks and classes were held two times per week (four hours per class). Design research can be applied across a project process but this paper focuses on utilising design research tools to identify a problem in the early stages of a project.

\subsection{Data process}

Three surveys were conducted for this study. The same surveys were used to ask the students to identify the difference in proportion of the research phase before and after the project. Specifically, the questions had two strands: 1) the proportion of each stage (phase 1: orientation and research for understanding a project, phase 2: strategy and exploration for concept development, phase 3: development and refinement, and phase 4: production (delivery)) which students allotted, and 2) the tools that the students used in each stage. This process applied here is similar in concept to the 'Double Diamond' design process. To have a more objective view, the workbooks that each group presented after class were reviewed to check their tools used in the project. Also, in this paper, the research phase is defined by embracing both 'phase 1: orientation and research' and 'phase 2: strategy and exploration'.

The last survey was undertaken with six experts in order to evaluate the students' work: experts comprised three from academia and three from design practice who have experience between 7-over 10 years). The questionnaire was adapted from an existing one used in the previous research ([24], many studies use this measurement scheme). The measurement scheme has three themes - originality, usefulness, and appeal - and each theme has three items and a seven-point semantic scale: 1) originality: "unique" (7) to "ordinary" (1); "original" (7) to "commonplace" (1); "fresh" (7) to "routine" (1); 2) usefulness: "useful" (7) to "useless" (1); "effective" (7) to "ineffective" (1); "worthwhile" (7) to "worthless" (1); 3) appeal: "appealing" (7) to "unappealing" (1); "likeable" (7) to "not likeable" (1); 
"desirable" (7) to "undesirable" (1).

To analyse the survey data in this study, SPSS 21 was used for the preliminary analysis and AMOS 7.0 for structural equation modelling. Except for the preliminary analysis, the means and usages of each group were applied for the analyses. In the first survey, two groups only had two of three students' data: therefore, for these two groups, the means of two students' data rather than three were applied to analysis. The hypotheses were tested and an alternative explanation was included via a structural equation model. This technique is appropriate to study complex relationships among variables where some variables can be hypothetical or unobserved for experimental test.

\section{Results}

This section has twofold: 1) preliminary analysis to understand how students undertake the research phase before identifying a problem, and 2) primary analysis to test hypotheses.

\subsection{Preliminary analysis}

A paired T-test was conducted to understand previous students' ways of conducting the research process. Each phase of 'before and after the project' was compared to see differences as well as phases being combined together (phases $1 \& 2$ and phases $3 \&$ 4). Amongst the two sets, the difference between the means of 'after $1 \& 2$ ' and 'before $1 \& 2$ ' was 2.38 $(\mathrm{SD}=4.57)$ with $\mathrm{t}=2.326(\mathrm{p}=0.031)$, which is statistically significant. This shows that 'after $1 \& 2$ ', where most research was conducted with empathy, accounts for more means. Therefore, the different circumstances between the 'before' and 'after' analyses appear to have had a positive effect on post-analysis. In contrast, the difference in the means of 'before and after $3 \& 4$ ' was $-2.63 \quad(\mathrm{SD}=4.47)$ with $\mathrm{t}=-2.627 \quad(\mathrm{p}=0.017)$, which is statistically significant. This shows that the different circumstances between pre $^{-}$and post-analysis had a negative effect. This implies that, during this project, the proportion of phases in which research was undertaken increased.

[Table 1] T-test of research phases

\begin{tabular}{c|c|c|c|c}
\hline & Mean & $\mathrm{SD}$ & $\mathrm{t}$ & $\mathrm{p}$-value \\
\hline \hline $\begin{array}{c}\text { After: phases 1 \& } 2- \\
\text { Before: phases 1 \& } 2\end{array}$ & 2.38 & 4.57 & 2.326 & 0.031 \\
\hline $\begin{array}{c}\text { After: phases 3 \& } 4- \\
\text { Before: phases 3 \& 4 }\end{array}$ & -2.63 & 4.47 & -2.627 & 0.017 \\
\hline
\end{tabular}

In terms of the quality of undertaking tools before this project, when students were asked to identify the tools and methods used in phases 1 and 2, they indicated mostly using general and passive ones, such as Internet research and desk research in the form of book and other literature (see Fig. 2 and Fig. 3). Although desk research includes Internet research, almost half of the students utilised Internet research, as depicted in Fig. 2, and with the intention of stressing this finding, Internet research is delineated separately. To summarise, it can be assumed that they had rarely chance to learn or apply diverse methods involving design research.

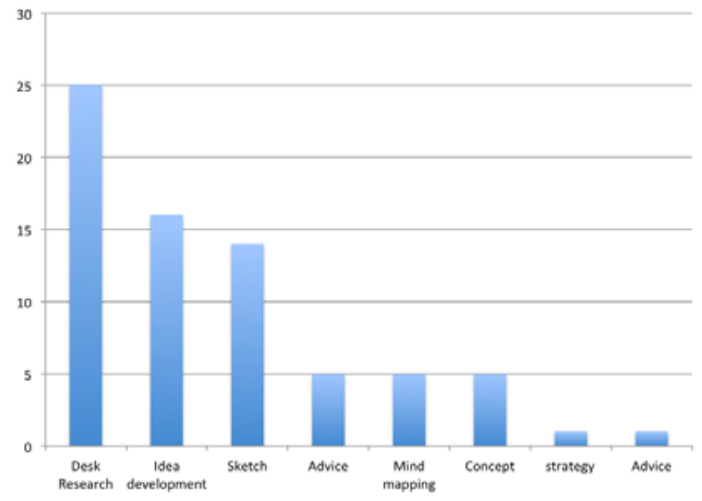

[Fig. 2] Tools used in phase 1: Plural responses 


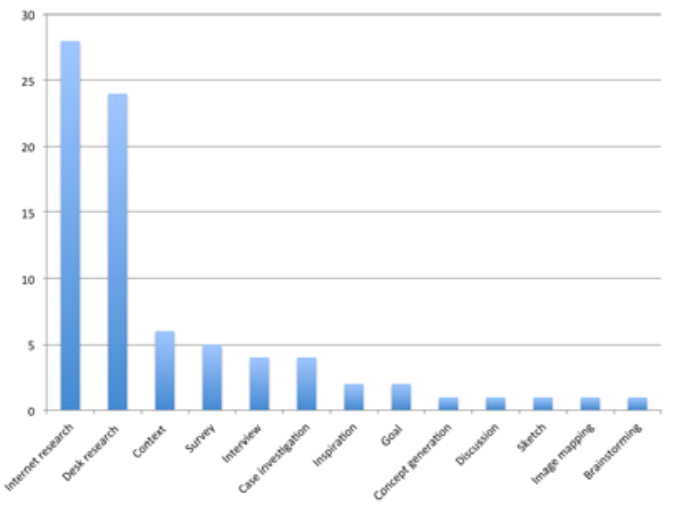

[Fig. 3] Tools used in phase 2: Plural responses

\subsection{Test of hypotheses}

The structural model includes all the hypothetical paths which show statistical significance (illustrated by Table 2 and Table 4, and Fig. 4 and Fig. 6 in this subsection below). Only $\mathrm{H} 1$ does not show an increase in the research phase, while 'after phases 1 \& 2' accounts for a better direct outcome. Despite the failure in satisfaction of $\mathrm{H1}$, the model above shows that increasing the proportion of the research phase and choosing design way results in better evaluation of usefulness throughout the paths (see Fig. 4).

$\mathrm{H} 2$ and $\mathrm{H} 4$ are supported by the model depicted in Table 2 and Fig. 4. First, in terms of H2, higher means of 'after $1 \& 2$ ' results in a greater chance of choosing a design way, with standard estimate being 0.414 $(\mathrm{p}=0.048)$. However, since there is no statistical significance when choosing classical ways, adopting classical ways is omitted in the structural model. Subsequently, those students who chose design ways had a higher chance of also choosing 'observation (seeing)' and 'doing' tools. Each standard estimate was $0.784(\mathrm{p}<0.000)$ and $0.526(\mathrm{p}=0.007)$, respectively. In terms of H3, tools - 'observation and doing' - already belong to design ways and shows an obvious effect on choosing a subsequent effect.

Secondly, in terms of H4, adopting 'observation (seeing)' tools impacts on 'usefulness' amongst 3 assessments for the measurement of outcomes as dependent variables; the standard estimate was 0.519 $(\mathrm{p}=0.008)$, which is statistically significant. Absolute fit values for the model below (Fig. 4) account for root mean squares residuals $(\mathrm{RMR})=0.097$, the Tucker-Lewis coefficient (TLI) $=1.33$ and root mean square error of approximation (RMSES) $=0.000$, which shows that all figures, with the exception of root mean squares residuals $(\mathrm{RMG})(<0.05)$, indicate goodness of fit.

[Table 2] Experiment 1: test of hypothesis

\begin{tabular}{c|c|c|c|c}
\hline After: phases 1 \& 2 means & $\begin{array}{c}\text { Standard } \\
\text { Estimate }\end{array}$ & S.E & C.R & p-value \\
\hline $\begin{array}{c}\text { After: phases 1 \& 2 means } \\
\rightarrow \text { Design ways }\end{array}$ & 0.414 & 0.079 & 1.980 & 0.048 \\
\hline $\begin{array}{c}\text { Design ways } \rightarrow \\
\text { Observation (seeing) }\end{array}$ & 0.784 & 0.104 & 5.512 & $* * *$ \\
\hline \begin{tabular}{c} 
design ways $\rightarrow$ doing \\
\hline $\begin{array}{c}\text { Observation (seeing) } \rightarrow \\
\text { Usefulness }\end{array}$
\end{tabular} & 0.526 & 0.082 & 2.696 & 0.007 \\
\hline
\end{tabular}

Chi-square $=3.186$ (df=6, $\mathrm{p}=0.785)$, goodness of fit $(\mathrm{GFI})=0.938$, adjusted goodness of fit (AGFI) $=0.844$, normed fit index $(\mathrm{NFI})=0.914$, comparative fit index $(\mathrm{CFI})=1.000$, root mean squares residuals $(\mathrm{RMR})=0.062$, Tucker-Lewis coefficient $(\mathrm{TLI})=1.174$, root mean square error of approximation (RMSEA) $=0.000$

$* * * \mathrm{p}<0.000$

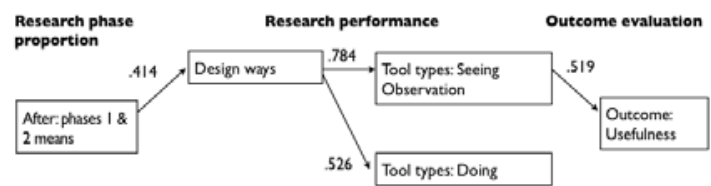

[Fig. 4] Results: Structural model

In terms of $\mathrm{H} 3$, while employing classical ways does not always account for any effect on outcomes in this study, applying design ways shows a direct effect on 'usefulness' (see Table 3 and Fig. 5). This means that groups which adopt more design ways show higher values for outcome assessment, 'usefulness', its standard estimate is $0.476 \quad(\mathrm{p}<0.018)$. This model's fitness level is Chi-square $=0.157(\mathrm{df}=1, \mathrm{p}=0.692)$, GFI $=0.995, \quad$ AGFI $=0.967, \quad$ NFI $=0.982, \quad$ CFI $=1.000$, $\mathrm{RMR}=0.060$, TLI $=1.450$ RMSEA $=0.000$, which shows a very positive level of suitability, with the exception of RMG $(<0.05)$, thus this shows goodness of fit. 
[Table 3] Experiment 2: test of hypothesis

\begin{tabular}{c|c|c|c|c}
\hline After: phases $1 \& 2$ means & $\begin{array}{c}\text { Standard } \\
\text { Estimate }\end{array}$ & S.E & C.R & p-value \\
\hline $\begin{array}{c}\text { After: phases 1 \& } 2 \text { means } \\
\rightarrow \text { Design ways }\end{array}$ & 0.414 & 0.079 & 1.980 & 0.048 \\
\hline $\begin{array}{c}\text { Design ways } \rightarrow \\
\text { Usefulness }\end{array}$ & 0.476 & 0.119 & 2.362 & 0.018 \\
\hline
\end{tabular}

Chi-square $=.157 \quad(\mathrm{df}=1, \quad \mathrm{p}=0.692), \quad \mathrm{GFI}=.995, \quad \mathrm{AGFI}=.967, \quad \mathrm{NFI}=.982$, $\mathrm{CFI}=1.000, \mathrm{RMR}=.060$, TLI $=1.450, \mathrm{RMSEA}=.000$

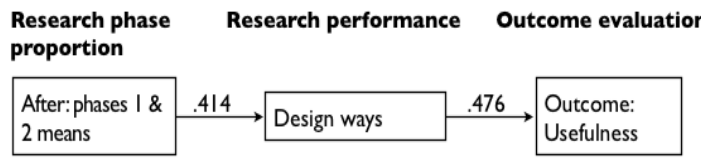

[Fig. 5] Results: structural model

'Usefulness' had an influence on other evaluation assessments (see Table 4 and Fig. 6). After further analysis, higher 'usefulness' value influenced a higher 'appealing' value, and its standard estimate was 0.899 ( $\mathrm{p}<0.000$ ). Subsequently, the higher 'appealing' grade influenced a higher 'originality' grade, its standard estimate is $0.822(\mathrm{p}<0.000)$. This model's fitness level is Chi-square $=0.745 \quad(\mathrm{df}=1, \quad \mathrm{p}=0.388), \quad \mathrm{GFI}=0.975$, AGFI $=0.850, \quad \mathrm{NFI}=0.986, \quad \mathrm{CFI}=1.000, \quad \mathrm{RMR}=0.008$, TLI $=1.015$, RMSEA $=0.000$, which shows a very positive level of suitability. The model above is close to the saturated model.

[Table 4] Experiment 3: test of hypothesis

\begin{tabular}{l|c|c|c|c}
\hline Usefulness & $\begin{array}{c}\text { Standard } \\
\text { Estimate }\end{array}$ & S.E & C.R & $\mathrm{p}$-value \\
\hline \hline Usefulness $\rightarrow$ Appealing & 0.899 & 0.899 & 8.962 & $* * *$ \\
\hline Appealing $\rightarrow$ Originality & 0.822 & 0.105 & 6.287 & $* * *$ \\
\hline
\end{tabular}

Chi-square $=0.745 \quad(\mathrm{df}=1, \mathrm{p}=0.388), \mathrm{GFI}=0.975, \mathrm{AGFI}=0.850, \mathrm{NFI}=0.986$, $\mathrm{CFI}=1.000, \mathrm{RMR}=0.008, \mathrm{TLI}=1.015$, RMSEA $=0.000$

$* * * \mathrm{p}<0.000$

Outcome evaluation

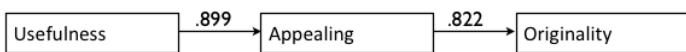

[Fig. 6] Results: structural model
Previous variables do not impact each assessment of measurement but do impact on 'usefulness' and accordingly elicited a path to other assessments: 'appealing and originality'. Therefore, it can be assumed that applying design ways - especially 'observation (seeing)' - accounts for a positive impact on outcomes throughout the paths.

\section{Discussion}

From the T-test and descriptive analysis, it can be interpreted that, before this project, students had a smaller proportion for the research phase and ways of conducting research were very limited. Most of all, in terms of the quality of research, most students used Internet research or a literature review and rarely went to conduct field work or engage with people: students were mostly conducting research in front of their computers. Only some of them applied classical research ways: survey or interviews.

Through experimenting of hypotheses, except for $\mathrm{H} 1$, all the hypotheses were supported: even $\mathrm{H} 1$ shows a path to 'usefulness'. Thus, from the results supported by the analyses, it can be interpreted that:

1. Groups which have a greater research proportion - a greater proportion in phases $1 \& 2$ - show a path to a positive evaluation of the usefulness of outcomes. Subsequently, the groups which show a more positive evaluation of usefulness account for a more positive evaluation of appealing and originality.

2. Groups which have a greater research proportion show a direct effect on ways of choosing design methods for research rather than classical ways. It can be interpreted that more utilisation of design methods might require a greater research proportion.

3. More utilisation of design tools shows an effect on positive evaluation in terms of 'usefulness', and this reaffirms that applying design tools in the research phase results in better outcomes, which is asserted in the theoretical background. 
4. Between two design tools - 'observation and doing' - the groups which used more 'observation' tools saw a direct effect on positive outcome evaluations rather than 'doing' tools.

Therefore, this study posits that more utilisation of design tools in the research phase can result in a more positive evaluation of 'usefulness'; the more positive evaluation of 'usefulness' that groups have, the more positive the evaluation for the other criteria: 'originality and appealing'. Eventually, using design tools in the research phase generates better outcomes.

Another interesting finding is captured in this study. According to Sanders and Stappers, engaging in 'doing' tools helps to identify latent needs and desires through people's participation [14]. There is no effect of 'doing' tools on outcomes but the 'observation' tool unilaterally shows an effect on 'usefulness'. However, it cannot be strongly asserted here that the 'doing tools' effect on outcome is due to the following considerations. 1) Despite being statistically valid, fewer groups used 'doing' tools: thirteen groups used 'observation' tools whereas seven groups used 'doing' tools. 2) In addition, utilisation of 'doing' tools requires experiences of applying such tools and complete preparation, such as place, member, toolkit, etc. Since students had not used design methods before, it was unrealistic for students to have a good command of tools; they hardly coped with employing tools at the beginning of the project. This finding asserts that 'observation' tools are more accessible to students to calibrate for research at first.

\section{Conclusion}

This study elaborates how outcomes can be derived from research into design. From the analyses, previously students were not engaged with people or real life. They leant strongly on secondary research, such as Internet research or literature, so that, comparatively, quality and the proportion of the research phase in the project were not buoyant.
Nevertheless, this study substantiates that research using design tools - especially 'observation' - results in positive outcomes. This paper demystifies unclear intentions and the effect of design research and envisions design ways in the research phase leading to pragmatic and favourable outcomes.

Breslin and Buchanan advocate that, "this [expansion] does not reduce our respect for graphic products and industrial products, but places them in a new context for design thinking" [25, pp.40]. A way of conducting research phase and design tools will be utilised to different degrees depending on project types, but it is important to underline the vital role of human engagement in the research phase for design's expansion towards taking a role to develop a system, environment and organisation for human experience and interaction.

\section{Reference}

[1] Bruce, M., \& Bessant, J. (2002). Design in business: Strategic innovation through design. UK: Pearson Education.

[2] Frascara, J. (1988). Graphic design: Fine art or social science? Design Issues, 18-29.

DOI: http://dx.doi.org/10.2307/1511556

[3] Buchanan, R. (2001). Design research and the new learning. Design Issues, 17(4), 3-23.

DOI: http://dx.doi.org/10.1162/07479360152681056

[4] Buchanan, R. (1992). Wicked problems in design thinking. Design Issues, 8(2), 5-21.

DOI: http://dx.doi.org/10.2307/1511637

[5] Roth, S. (1999). The state of design research. Design Issues, 15(2), 18-26.

DOI: http://dx.doi.org/10.2307/1511839

[6] Buchanan, R. (1998). Branzi's dilemma: Design in contemporary culture. Design Issues, 14(1), 3-20.

DOI: http://dx.doi.org/10.2307/1511825

[7] Bennett, A. (2012). Good design is good social change: Envisioning an age of accountability in communication design. Visible Language, 46(1/2), 66-79.

[8] Bennett, A. (2006). The rise of research in graphic design. In A. Bennett (Ed.), Design studies: Theory and research in graphic design (pp. 14-25). New York: Princeton 
Architectural Press.

[9] Forlizzi, J., \& Lebbon, C. (2002). From formalism to social significance in communication design. Design Issues, 18(4), 3-13.

DOI: http://dx.doi.org/10.1162/074793602320827389

[10] Tyler, A. (2006). Educating design citizens: Passing on a mind, body, spirit practice. In A. Bennett (Ed.), Design studies: Theory and research in graphic design (pp. 333-353). New York: Princeton Arc

[11] Koskinen, I., Zimmerman, J., Binder, T., Redstrom, J., \& Wensveen, S. (2011). Design research through practice from the lab, field, and showroom. Waltham, MA: Elsevier.

[12] Morrison, A. (2013). Norwegian optimism about the future of design research. Swedish Design Research Journal, 1, 4-12.

[13] Frayling, C. (1993). Research in art and design. Royal College of Art Research Papers, 1, 1-5.

[14] Sanders, E.B.-N., \& Stappers J. P. (2012). Convivial design toolbox: Generative research for the front end of design. Amsterdam; Enfield: BIS; Publishers Group UK [distributor].

[15] Collins, H. (2010). Research methods in design management. Lausanne: AVA Publishing.

[16] Swann, C. (2002). Action research and the practice of design. Design Issues, 18(1), 49-61.

DOI: http://dx.doi.org/10.1162/07479360252756287

[17] Brown, T. (2009). Change by design: How design thinking transforms organizations and inspires innovation. NY, USA: HarperCollins.

[18] Lunenfeld, P. (2003). The design cluster. In B. Laurel (Ed.), Design research: Methods and perspectives (pp. 10-15). Mass: The MIT Press.

[19] Heller, A. (2006). Shaping belief: The role of audience. In A. Bennett (Ed.), Design studies: Theory and research in graphic design (pp. 10-13). New York: Princeton Architectural Press.

[20] Sanders, E.B.-N. (2002). From user-centered to participatory design approaches. In J. Frascara (Ed.), Design and the Social Sciences: Making Connections (pp. 1-8). New York: Taylor and Francis.

DOI: http://dx.doi.org/10.1201/9780203301302.ch1

[21] Mintzberg, H., \& Westley, F. (2001). It's not what you think. MIT Sloan Management Review, 42(3), 89-93.

[22] Beverland, M. (2010). Right-Wing customers - the enemy of innovation. Design Management Review, 21(3), 64-71.

DOI: http://dx.doi.org/10.1111/j.1948-7169.2010.00081.x

[23] Verganti, R. (2009). Design-driven innovation: Changing the rules of competition by radically innovating what things mean. Boston, Mass. Harvard Business Press.

[24] Dahl, D. W., Chattopadhyay, A., \& Gorn, G. J. (1999). The use of visual mental imagery in new product design. Journal of Marketing Research (JMR), 36(1), 18-28. DOI: http://dx.doi.org/10.2307/3151912

[25] Breslin, M., \& Buchanan, R. (2008). On the case study method of research and teaching in design. Design Issues, 24(1), 36-40.

DOI: http://dx.doi.org/10.1162/desi.2008.24.1.36

\section{Younjoon Lee}

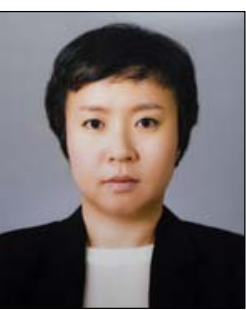

- May 2002 : Pratt Institute, Graduate School, Visual Communication Design, MS

- Mar. 2013 : Lancaster University, $\mathrm{PhD}$ in Design

- Nov. 2003 Jun. 2006 : GAID

Associates, Design Director - Jan. $2007 \sim$ Aug. 2008 : Interbrand, Senior Designer

- Sep. $2013 \sim$ current : Hongik Univ., Visual Communication Design, Assistant Professor

$<$ Research Interests $>$

Design Research, Design Management, Service Design, Brand Development 